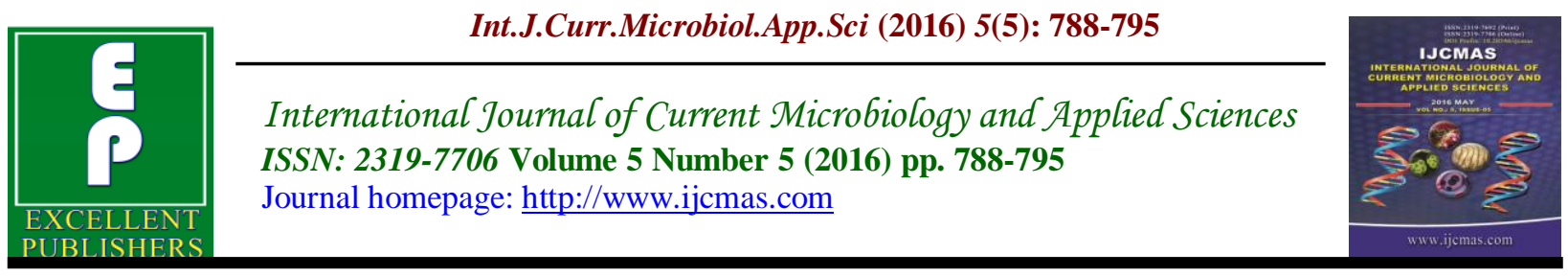

Original Research Article

http://dx.doi.org/10.20546/ijcmas.2016.505.079

\title{
Effect of Anabolic Steroid in Accelerating Healing Process of Experimentally Fractured Tibia of Rats and Compare its Fracture Healing Property with Terminalia arjuna
}

\author{
Giri Reena $^{1^{*}}$, Giri Kiran ${ }^{2}$ and Palandurkar Kamlesh ${ }^{3}$ \\ ${ }^{1}$ Department of Pharmacology, GMC, Medical College, Rajnandgaon, CG, India \\ ${ }^{2}$ Department of Pharmacology, BHU, India \\ ${ }^{3}$ Department of Biochemistry, BHU, India \\ *Corresponding author
}

A B S T R A C T

Musculoskeletal injuries existed throughout human history."Fracture" defined as a break in the continuity of the bone. Prolonged period required for healing of fractures entails much suffering \& economic loss to the patient. Varied products from vitamins to hormones - tried to hasten the process of bone healing unfortunately without positive outcome. Arjun tree with its roots in Indian

Keywords

3-point

bending, radiological examination.

Article Info

Accepted:

20 April 2016

Available Online:

10 May 2016 mythology, known to have good effects on bone healing from many centuries. Anabolic steroids, are a class of steroid hormones related to the hormone testosterone. They increases protein synthesis within cells, which results in the building up of cellular tissue. Except few studies, no extensive investigations have been made for improving this inherent biological phenomenon of bone healing. Hence, the research question was formulated as "whether the herb Arjuna terminalia \& anabolic steroid induce favorable response in bone healing \& to evaluate their fracture healing property radiologically. In our study we induce fracture in 16 wistar albino rats of either sex using 3-point bending method. Two treatment groups made as Terminalia arjuna \& anabolic steroid group. Treatment given for 4 weeks \& rats investigated radiologically for fracture healing phenomenon. Terminalia arjuna treated animals revealed faster initiation of healing process than anabolic steroid treated group. Healing was almost complete within four weeks of fracture in Terminalia arjuna treated animals \& remained incomplete in anabolic steroid treated animals. Our study indicates - daily administration of an alcoholic extract of Arjuna terminalia orally in the dosage of $500 \mathrm{mg} / \mathrm{kg}$ has definite action on the rate of healing of fractures.

\section{Introduction}

Evidence of musculoskeletal injuries has been found in archaeological studies as early as 5000 years ago (1). In today's modern industrial era a high energy industrial, vehicular, ballistic or bomb fracture and many other causes have been of added for the causation of poly-trauma. (2) In human beings the healing of a fracture is a complex physiological process of bone regeneration. The fracture heals by callus formation in endochondral 
ossification \& it takes place after preliminary formation of cartilage while endosteal healing occurs as a part of a constant remodeling process. The prolonged period is required for healing of fractures. This entails much suffering \& economic loss to the patient. Therefore, it has all along been the endeavour of scientists to find out certain agents which may hasten healing \& thereby shorten the duration of convalescence (3).

Traditional \& ayurvedic medicines have been tried since senturies (4)Taking into consideration of this and stimulated by this we selected herbal agent Terminalia arjuna(TA)which is entirely indigenous to this country and which has been known to have good effects on bone healing since the past many centuries. The only promising agent amongst the hormones showing some beneficial effect in healing of fracture has been shown to be the anabolic hormone derived from the androgenic hormone of the testes. Hence we selected anabolic steroid (Nandrolone decanoate-[Decaduraboline] (AS) as our another agent in our study.

Arjuna is an Ayurvedic herb that has been a part of ayurveda since prehistoric times. (5) Arjuna was first described by Vagbhata.As per Bhava Prakasha, a famous ayurvedic expert in ancient India, it is a herb that is of cool temperament. Terminalia arjuna belongs to family Combretaceae.Charaka Samhita and Ashtang Hridayam mentioned about its ayurvedic properties and different uses.(5)

Another famous sage of older times Charakdatta has recommended the use of arjuna with milk in conditions like cardiac disorders indigestion, fever, haemorrages, bleeding and most importantly the fractures and related injuries.(6)The bark paste of Terminalia arjuna plant is being successfully used for the treatment of fractured bone of animals as well as human being.(7) It helps in wound healing and joining by astringent property. It is haemostatic. The bark paste is locally applied on wounds, ulcer and specially used in promoting the union of fractures. That is, internally and externally, Arjuna is very efffective in promoting the healing of broken bones. It is believed that the fracture bones can be regenerated in a faster rate if the bark paste is used and plastered with the bark itself. (7)

Anabolic steroids, also known as anabolicandrogenic steroids are a class of steroid hormones related to the hormone testosterone.They increases protein synthesis within cells, which results in the building up of cellular tissue.(8) Nandrolone [19-nortestosterone] is an anabolic steroid that may be present naturally in the human body, albeit in minute quantities of less than $0.4 \mathrm{ng} / \mathrm{ml}$. Deca-Duraboline is actually the brand name for the Nandrolone decanoate. Nandrolone does not produce many estrogenic \& androgenic side effects. (9)

The therapeutic profile on bone of Nandrolone decanoate is that of inhibitor of bone resorption with temporary increase in bone formation, followed by an absence of suppression of bone formation, indicating uncoupling of bone resorption $\&$ formation. This results in an increase in bone mineral content. Furthermore, Nandrolone decanoate increases calcium balance \& muscle mass. It increases the local production of growth factors in bone in experimental conditions, indicating an improvement of bone quality. $(10,11$, 12)Nandrolone is a relatively safe drug with minimal androgenic concerns and ample anabolic action at therapeutic doses. 
Plant extracts are attractive sources of new drugs and have been shown to produce promising results. It was considered worthwhile to investigate whether the above mentioned herb (Terminalia arjuna) \& Anabolic steroid induces its favourable responses in bone healing as judged by radiological examination.

The present study was undertaken to evaluate whether Terminalia arjuna and anabolic steroid promote fracture healing and compare their property of fracture healing in experimental animals (rats), also to assess the time required for fracture healing with above mentioned herb and anabolic steroid.

\section{Materials and Methods}

The present study was conducted in Department of pharmacology, Jawaharlal Nehru Medical College, Sawangi (Meghe), Wardha. The research protocol was approved by the Institutional Animal Ethical Committee, Jawaharlal Nehru Medical College, Sawangi (Meghe),Wardha.The plants were identified \& authenticated with the standard sample preserved as Terminalia arjuna by Botany Department, R.T.M.Nagpur University,Nagpur. Maharashtra, India

The study was conducted using 24 Wistar Albino Rats, of either sex weighing 150$200 \mathrm{~g}$ purchased from Institute of Pharmaceutical Education \& Research Borgaon (Meghe),Wardha. Maharashtra, India.

Preparation of Ethanolic extract of Bark of Terminalia arjuna:Dried arjuna was coarsely powered and $4 \mathrm{~kg}$ of coarse powered of Terminalia arjuna was soaked in $6 \mathrm{~L}$ of ethanol for $48 \mathrm{~h}$, and the extract was filtered and allowed to dry at room temperature. The last traces of solvent were removed under vaccum drier. The brown powdered mass obtained, which was pulverized and sieved. Then stored at $-40 \mathrm{C}$ until further use. (7) For administration,the extract was suspended in freshly prepared sugar water. (13)

\section{Phytochemical Screening}

The preliminary phytochemical studies done at Laboratory of Department of Pharmacognosy, R.T.M. Nagpur University, Preliminary phytochemical studies of Terminalia arjuna shows the presence of Tannins,Saponins and Carbohydrates in the extracts.

\section{Acclimatization}

Animals were acclimatized for 8 days in the laboratory before experiment. Animals were kept on standard nutritional \& environmental condition in separate cages. They were housed under standard condition of light,temperature \& humidity. They were fed with standard laboratory chow \& provided with water ad libitum.

Grouping of Animals - Animals were divided into 3 groups of eight animals each.

Group I - Control group [NS group] Animals in the group received Normal saline $(2 \mathrm{ml} / \mathrm{kg})$ orally for 30 days.

Group II - Treatment group [TA group] This group received extracts of Terminalia arjuna with sugar water orally $(500 \mathrm{mg} / \mathrm{kg}$ body weight) bd, for 30 days.

Group III - Treatment group [AS group] This group received Nandrolne decanoate, (48mg/kg body weight) od, IM, twice weekly for 30 days. 


\section{Pre-Surgical Evaluation}

Before surgery every rat was subjected to clinical orthopaedic evaluation and dorsopalmar radiographic views of the left tibia were obtained (44 KW, $160 \mathrm{~mA}, 5$ $\mathrm{mAs}, 0.26 \mathrm{~s})$. (14)

\section{Surgery for Creating Tibial Fracture}

Animals were anaesthetized with Phenobarbitone $60 \mathrm{mg} / \mathrm{kg}, \mathrm{IP}$ and Ketamine [Anikate,40 mg/kg ,IP]. Then closed transverse fracture of the mid - diaphysis of left tibia were created in all three groups by three point bending method (15). These fractured limb were stabilized with splints after reduction and animals were allowed to move freely after recovering from anaesthesia.

\section{Treatment Protocol for Fracture Healing}

\section{Determination of Doses}

1.Terminalia arjuna - $500 \mathrm{mg} / \mathrm{kg}$ body weight

2.Anabolic steroid - $48 \mathrm{mg} / \mathrm{kg}$ body weight.

\section{Preparation of Working Solution}

The required amount of powdered extract of Terminalia arjuna measured as per the dose $/$ bodyweight $(500 \mathrm{mg} / \mathrm{kg})$ of rats daily using $8 \mathrm{ml}$ of freshly prepared sugar water solution.

\section{Radiological Evaluation}

The animals were evaluated clinically every day to determine general condition and lameness. Lameness was evaluated by observing each animal moving freely in the cage .Bone healing of control group and drug treated group was followed in each animal by radiographic evaluation immediately after surgery and every week thereafter for 4 weeks using the same technique . Qualitative assessment included fracture line/margins, fracture gap, external callus appearance, callus-tocortex ratio, bridging, and radiologic union done by radiographic evaluation.

\section{Results and Discussion}

\section{Radiological findings}

The findings of radiological pictures taken at weekly intervals are as follows,

1st week

X-ray did not reveal any marked difference in the various groups [ TA, AS, NS]. The fragments were freely mobile. Broken ends were still visible on $\mathrm{x}$-ray. This is a fibroblastic phase. Plate 1

\section{2nd week}

The skiagram showed beginning of callus formation and bridging of gap in TA treated groups but no such results observed in AS \& NS treated groups, there the gap was still visible.This is a collagen phase Mobility of fragments still present to certain extent. Plate 2

\section{3rd week}

The x-ray showed greater amount of calcification of callus in TA treated group in which one could hardly see a gap at the fracture site, fragments could not be elicited whereas in other groups[AS, NS] some gap was still visible. This is an osteogenic phase. Plate 3 


\section{4th week}

In the skiagram there was an evidence of union in TA treated groups. Almost complete bridging of the fracture ends

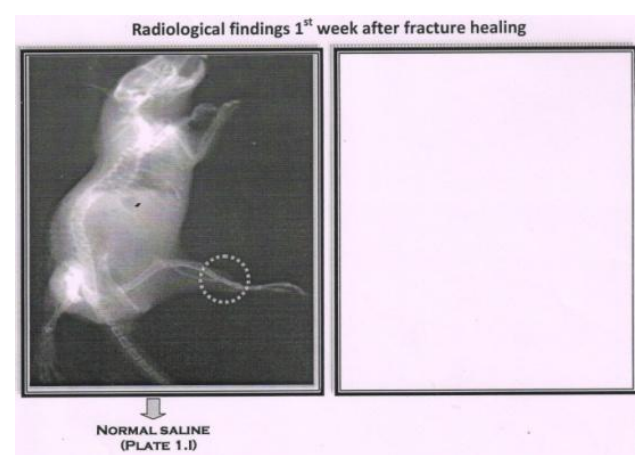

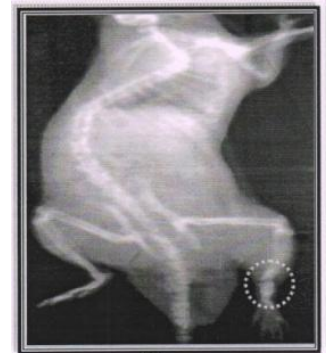

ARJuna TERMinauA

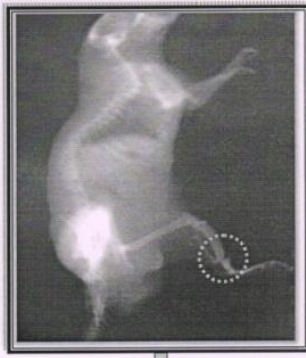

ANABOUIC STEROID

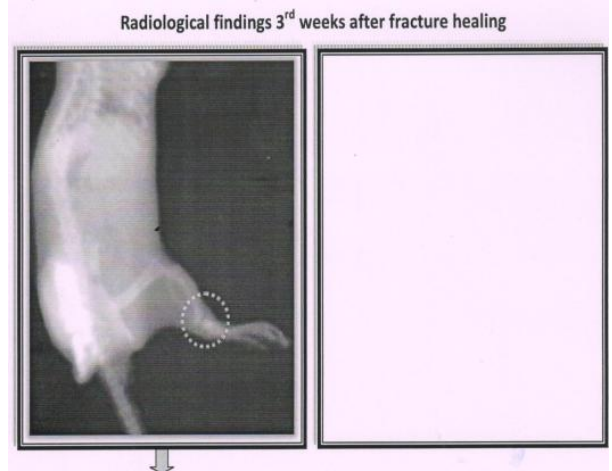

NORMAL SALINE
(PLATE 3.1)

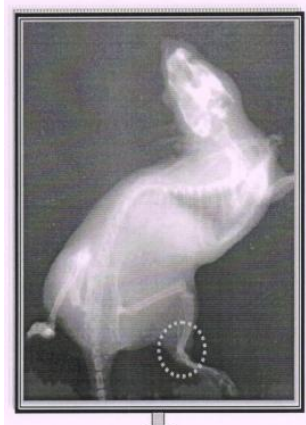

ARJUNA TERMINALAA

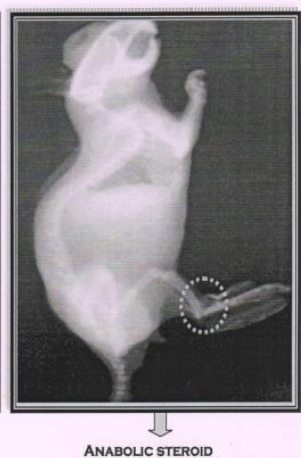

with extensive bony deposition compared to that of anabolic steroid treated \& control [Normal saline] group is seen in TA treated groups. This is also an osteogenic phase. Plate 4.
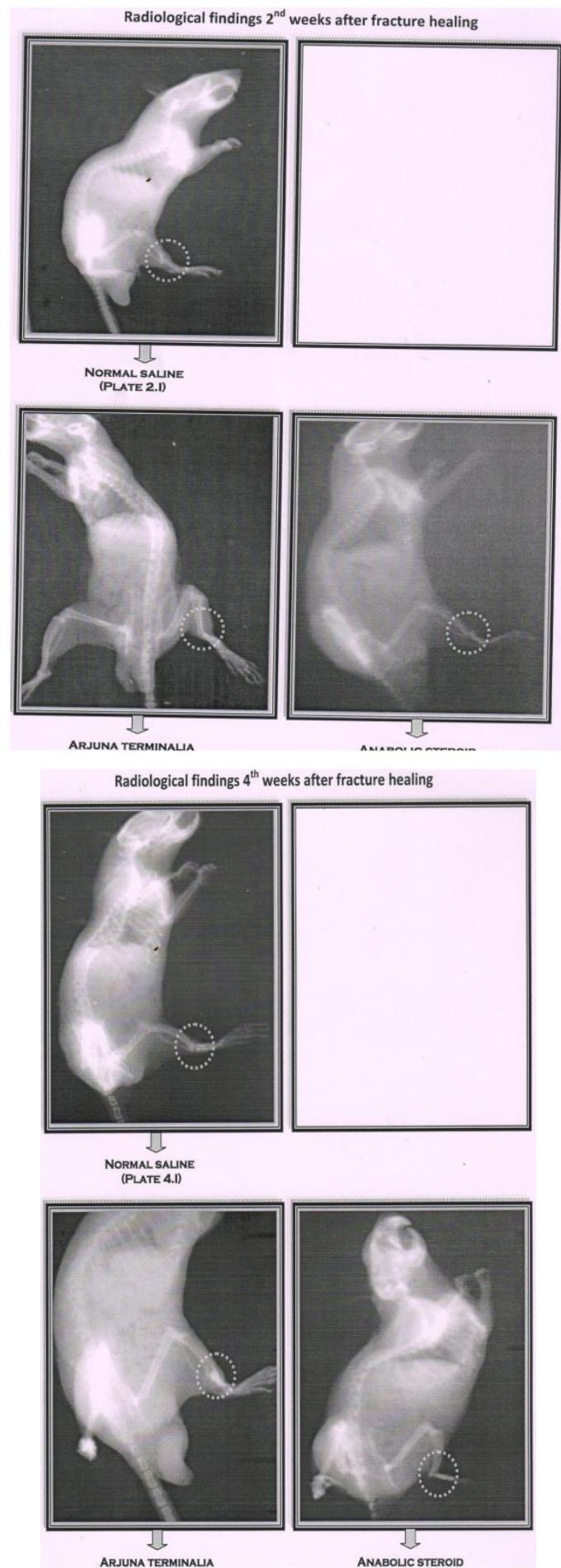
The above findings convincingly demonstrated that the herb Terminalia arjuna have some definite influence in the rate of fracture healing.

As mentioned by Singh DV et al 2004, tribal healers used the bark paste of arjuna plant successfully for the treatment of fractured bone of animals as well as human being of village area. (7) Terminalia arjuna when given with honey or sugar known to promote union of fractures. (6)Though these claims have been made since long to our knowledge, no scientific studies have been conducted so far to confirm or refute these long standing claims regarding Terminalia arjuna. These facts inspired us to evaluate fracture healing property of these agents. In our study we used Nandrolone decanoate an injectable preparation as third group. Thus it gave an opportunity for comparing its effects with Terminalia arjuna. It is well known since many centuries to the indigenous medical practitioners and also to the people working in jungles that a paste prepared from the herb TA applied to the injured limbs greatly helps in the healing of fractures. Further it was tried for internal use by way of drinking decoction prepared by boiling the fresh herb in milk. This indicated that the active ingredient might be a fat soluble substance.(7)Hence we prepared alcoholic extract for use in animals.

The callus formed in the rats treated with Terminalia arjuna was larger and denser than that of other two groups (Anabolic steroid and Normal saline) as evident from radiographs taken during 4th week. [Plate 4.] When Arjuna terminalia compared with the anabolic hormone, durabolin, herbal preparation are found to enhance the formation of callus whereas effect of Anabolic steroid preparation could not be demonstrated. The beneficial effects of Terminalia arjuna seem to be significant as promoter of the bone healing. [Plate.3,4]

We could not find any noticeable influence of Anabolic steroid Nandrolone decanoate on the fracture healing in our study conducted on experimental animals. Udupa $\mathrm{KN}$ et al 1960 also demonstrated the same in their study. (3)

Besides biological markers, radiography is an established method for evaluating fracture healing both in clinical use and in animal studies. Radiographs are able to visualize callus formation after mineralization.

Radiological findings in the present study demonstrated that, in all the three groups during first week there was no evidence of callus formation and the fragments were freely mobile. The fracture of second week of TA treated animals showed beginning of callus formation which is not so with anabolic steroid and normal saline treated group,mobility of fragments was also present to certain extent. During 3rd \& 4th weeks the callus progressively became harder and the movement between fragments could not be elicited in the herb treated group. Our results are in conformity to those found in the study of Guru Charan Prasad \& KN Udupa 1963. (16) At fourth week of fracture radiograph of the TA treated group revealed almost complete bridging of the fracture ends with extensive bony deposition and periosteal reaction in contrast to that of Anabolic steroid \& normal saline treated group. [Plate.4]

Ham AW 1974 also demonstrated similar radiographic evidence of early periosteal reaction and bony dissolution. (17) In our study we observed extensive bony deposition and periosteal reaction in Terminalia arjuna treated group. 
Our study indicates that daily administration of an alcoholic extract of Terminalia arjuna orally in the dosage of $500 \mathrm{mg} / \mathrm{kg}$ seems to have definite action on the rate of healing of fractures. The active substance responsible for the fracture healing property of Terminalia arjuna need to be investigated further to elucidated the precise modus operandus of this herb. There is much scope for detailed investigation on the use of various chemical substances in the biological phenomenon of fracture healing. The field of fracture which is a common problem in surgery has not been hitherto explored to the extent and it still remaining one of the most exciting subjects for further studies.

In conclusion, Proposition to administer Terminalia arjuna deserved to be explored in depth for defining its place in the overall management of fracture healing. No remarkable influence of anabolic steroid on the fracture healing in our study. Modus operandus of Terminalia arjuna need to explored further for the betterment of society.

\section{Acknowledgement}

Heartfelt gratitude to Mr. Rajaram A. Hire for his kind support in performing experiment \& throughout research work.

\section{References}

1. Perkins G. Principles of diagnosis \& management of fractures \& joint injuries. London, Oxford University Press.1948; 1-12.

2. Kulkarni GS. Fracture healing. Textbook of Orthopedics \& Trauma. 2(ed.) Jaypee Bothers Medical Publishers (P) LTD, 1993; 2:1193-1202.
3. Udupa KN, Arnikar HJ, Singh LM. Experimental studies of the use of cissus quadrangularis in healing of fracture. The Indian Journal of Medical Sciences. 1960; 551-557.

4. Vijay Thawani, Nitin Kimmatkar, Lal Hingorani, Rajkumar Khiyani. Effect of herbal combination containing $\mathrm{CQ}$ in fracture healing. The Antiseptic. Sept. 2002; (9):345-347.

5. Ramesh Chander, Kavita Singh, Khanna A.K, et al. Antidyslipidemic \& Antioxidant Activities of different fractions of Arjuna terminalia stem bark. Indian Journal of Clinical Biochemistry. July, 2004; 19 (2):141-148.

6. Tilak JC, Adhikari S. Radioprotective \& Antioxidant properties of Indian Medicinal plant, Arjuna terminalia. BARC Newsletter. Issue. 249:167-175.

7. Tanushree Patnaik, Dey RK, Panchanan Gounda. Isolation of Triterpenoid glycoside from bark of Arjuna terminalia using Chromatographic technique \& investigation of pharmacological behavior upon muscle tissue. E-Journal of Chemistry. 2007 October; 4: 474-479.

8. Anabolic steroid. Wikipedia.

9. Nandrolone decanoate. Wikipedia

10.Geusens F. Nandrolone Dacanoate. Pharmacological properties and therapeutic use in osteoporosis. Clinical rheumatology 1995; 14 (1) 3:32-39.

11.Aerssens J, Peeters J, Van den Eynde, R et al. The effect of nandrolone decanoate on IGF-I in rat bone. Fourth workshop on cells \& cytokines in bone \& cartilage, Davos, Switzerland, JANUARY. 1992; 11-14.

12.Dequeker, J, Mohan, S, Aerssens J, et al. Correspondence between bone IGF1 concentration \& bone density in both humans \& rats. Connective tissue research 1992; 27: 177.

13.Arjuna terminalia. Traditional uses of Arjuna terminalia. 
14.Antti Koivukangas. 2002. Effects of long-term clodronate administration on bone and on fracture healing in rat, with special reference to methodological aspects; Division of Orthopaedic and Trauma Surgery, University of Oulu. Chapter-2; 1-6.

15.Chuanyong $\mathrm{Lu}$ et al. Assessing angiogenesis during fracture healing. Iowa Orthop J. 2006; 26:17-26.
16.Guru Charan Prasad, Udupa KN. Effect of Cissus Quadragularis on the healing of cortisone treated fracture. Ind. Jour. Med. Res. July 1963; 51:667-676.

17.Ham AW. Histology. Philadelphia JB Lippincott company, 1974;433-435.

\section{How to cite this article:}

Giri Reena, Giri Kiran and Palandurkar Kamlesh. 2016. Effect of Anabolic Steroid in Accelerating Healing Process of Experimentally Fractured Tibia of Rats and Compare its Fracture Healing Property with Terminalia arjuna. Int.J.Curr.Microbiol.App.Sci. 5(5): 788795. doi: http://dx.doi.org/10.20546/ijcmas.2016.505.079 